\title{
Measuring visual symptoms in British cataract patients: the cataract symptom scale
}

\author{
H L Crabtree, A J Hildreth, J E O’Connell, P S Phelan, D Allen, C S Gray
}

\begin{abstract}
Aims-To develop and validate a scale for the measurement of visual symptoms and functional disability due to cataract in older UK residents.

Methods-In depth semistructured interviews were undertaken with 44 consecutive patients awaiting cataract surgery. Patients were asked to describe visual symptoms and problems with social functioning which were then incorporated into a questionnaire, the cataract symptom scale (CSS). The CSS was further examined in a cohort of 118 consecutive cataract patients awaiting surgery. Further assessments in these patients included visual acuity, visual function using an existing scale (the VF-14), activities of daily living, perceived health status, anxiety and depression, and a global assessment of how much patients felt their visual symptoms affected their daily life. Results-A 15 item scale was derived which was simple to administer to older patients and had a high internal consistency. The test-retest correlation coefficient for the total instrument score was $r=0.91$ $(p<0.0001)$. The CSS correlated well with the VF-14 and to a lesser extent with visual acuity in the better eye, activities of daily living, perceived health status, anxiety and depression, and the patients' global assessment of visual symptoms.

Conclusion-The CSS provides information regarding the symptomatic and functional status of older cataract patients resident in the UK which cannot be obtained by measurement of visual acuity alone.
\end{abstract}

(Br f Ophthalmol 1999;83:519-523)

Department of

Geriatric Medicine,

University of

Newcastle, Sunderland

Royal Hospital, Kayll

Road Sunderland,

Tyne and Wear,

SR4 7TP

$\mathrm{H}$ L Crabtree

A J Hildreth

J E O'Connell

C S Gray

Sunderland Eye

Infirmary, Queen

Alexandra Road,

Sunderland SR2 9HP

P S Phelan

D Allen

Correspondence to:

Professor C S Gray.

Accepted for publication

21 January 1999 ance and quality of life.
In current ophthalmological practice in the $\mathrm{UK}$, assessment of monocular visual acuity is used as the primary visual function test for judging the need for cataract surgery and for evaluating the success of the operation. ${ }^{2}$ However, there is evidence that thresholds for selection of patients for cataract extraction vary widely both across health districts and between consultant ophthalmologists. A study in the northern region of England found a wide range of visual acuity from $6 / 6$ to perception of light at the time of listing patients for cataract surgery. ${ }^{3}$ Monocular visual acuity is assessed using a Snellen chart, employing high contrast letters at a distance of 6 metres from the patient in an examination room free of glare. This does not represent normal everyday activities experienced by older people and it is not surprising that visual acuity has been shown to correlate poorly with patients' perception of visual disability due to their cataracts. ${ }^{45}$ Many patients have significant symptoms despite a normal visual acuity, and are as likely to show comparable improvements in symptoms and visual function following surgery as those with worse visual acuity. ${ }^{6}$ Assessment and prioritisation of patients for cataract surgery needs information in addition to visual acuity. However, review of medical notes has shown that information regarding the disability of the patient because of cataract and their functional status is not always recorded. ${ }^{37}$

Scales of visual function have been developed to elicit more information about functional limitation due to cataract symptoms. These include the VF-14, the activities of daily vision scale, Catquest and visual disabilities assessment. ${ }^{4-10}$ Such questionnaires incorporate an evaluation of problems with near vision, distance vision, glare disability, and driving and are intended to provide information on the everyday function of cataract patients. The VF-14 has been shown to correlate better with the patients' perceived trouble with vision and satisfaction with vision following cataract surgery than measures of Snellen visual acuity. ${ }^{11}$ However, the VF-14 was developed for use in the United States and may be limited in its applicability to the UK population, with a disproportionate emphasis on activities not regularly performed by older British residents - for example, driving (two out of 14 questions), hobbies, and sports such as tennis, golf, and bowling. The recently published Visual Disability Assessment ${ }^{10}$ also includes two questions on daytime and night-time driving and therefore may not be appropriate for use in many older UK residents. It is possible to remove questions from the VF-14-for example, removing the driving questions to 
form the VF-12 12 and removing further questions to form the VF-9, but there is some evidence that this may reduce the reliability of the VF-9. ${ }^{13}$ If the driving questions are excluded from the VF-14 the response rates to the VF-12 are only $25-60 \%$ in non-US populations. ${ }^{13}$

The objective of this study was therefore to develop a comprehensive instrument for routine use by primary healthcare professionals for the assessment of visual symptoms and functional impairment associated with ocular cataract in older people in the UK.

\section{Method}

SUBJECTS

Consecutive patients aged 65 years and above were recruited following referral to ophthalmology services at Sunderland Eye Infirmary with a confirmed diagnosis of age related cataract. All patients were under the care of a single ophthalmologist responsible for a geographically defined population (south Tyneside) and were listed for cataract extraction (either first or second eye) performed by phacoemulsification. Patients were enrolled in the study at their first preoperative consultation between September 1997 and July 1998 following written informed consent. Ethical approval for the study was obtained from the local research ethics committees for Sunderland and South Tyneside. Cognitive function was assessed in all patients using the Mini Mental State Examination $^{14}$ and those scoring less than 25 were excluded from the study.

DEVELOPMENT OF THE CATARACT SYMPTOM SCALE In depth semistructured interviews were undertaken in the patients' homes with the first 44 consecutive patients awaiting cataract surgery by the same researcher (HLC). The mean age of these patients was 76.6 years (SD 6.63), $82 \%$ were female and $59 \%$ were awaiting first eye surgery. The median visual acuity for the patients' better eye was $6 / 12$, for the worse eye was $6 / 24$, and for the eye to be operated on was $6 / 18$. Subjects were asked to describe visual symptoms and problems with social functioning that they attributed to their cataract(s) and these were ranked by patients according to importance and severity. These symptoms were abstracted from the interviews, and those occurring most frequently were incorporated into a questionnaire to form the cataract symptom scale (CSS). A heuristic approach was adopted for refinement of the scale in order to test patient and interviewer acceptability and comprehension. No subsequent problems were reported with the final version.

The CSS is an interviewer administered 15 item questionnaire designed to be used by a wide range of healthcare professionals in which patients are asked whether they have any difficulty performing certain tasks as a result of poor vision, with or without spectacles (see appendix). These items are graded on a five point scale. Where a patient is unable to perform a task or activity for reasons other than poor eyesight, that item is excluded from the analysis. The total score is calculated as a per- centage of the sum of the items scored by individual patients. For example, if a patient is unable to cross the road and negotiate the pavement because she is housebound, the total score for that patient is taken as a percentage of the remaining 13 items. A high score on the CSS indicates greater visual symptoms than a low score.

The CSS was then examined for test-retest reliability in a further cohort of 50 consecutive patients on two occasions 4 weeks apart. The test-retest correlation coefficient for the total instrument score was $r=0.91(\mathrm{p}<0.0001)$.

EVALUATION OF THE CSS

The CSS was further examined in a cohort of 118 consecutive cataract patients awaiting surgery, the first 50 of whom also participated in test-retest reliability. Visual acuity was recorded at the first hospital consultation and further assessments included the $\mathrm{VF}-14,{ }^{4}$ activities of daily living (Nottingham Extended ADL; NEADL), ${ }^{15}$ perceived health status (General Health Questionnaire 28; GHQ 28), ${ }^{16}$ and anxiety and depression (Hospital Anxiety and Depression Score; HAD).${ }^{17}$ Respondents were also asked for a global assessment of how much their visual symptoms affected their daily life, on a scale of $0-5$, ranging from $0=$ "no problems" to $5=$ "registered blind/need eyes of others". Other than visual acuity measurement all assessments took place in the patient's own home by the same observer.

\section{STATISTICS}

Initial data analysis and all other statistical analyses were performed using the Statistical Package for the Social Sciences (SPSS) for Windows Version 8. Testing of the data for normality was performed using the KolmogorovSmirnov test of normality. Test-retest reliability of the CSS was calculated using Spearman's rank correlation coefficient, while internal consistency was assessed using Cronbach's alpha. Comparisons between the CSS with visual acuity, VF-14, and other instruments were carried out using Spearman's rank correlation coefficient. Factor analysis was carried out using principal component extraction with Varimax rotation and Kaiser normalisation. The appropriateness of the factor analytic model was tested using the Kaiser-MeyerOlkin measure of sampling adequacy and Bartlett's test of sphericity.

\section{Results}

SUBJECTS

A total of 201 consecutive patients were enrolled into the study and 39 (with a score of less than 25 on the MMSE) were subsequently excluded. The remaining 162 had a mean age of 78 years (SD 6.16) with $69 \%$ female (113 patients). The majority of patients (101 patients, 63\%) were awaiting first eye surgery.

The median visual acuity for the patients' better eye was $6 / 9$, for the worse eye was $6 / 18$, and for the eye to be operated on was 6/18: 133 patients $(82 \%)$ had the eye with the worse visual acuity operated on. 
Table 1 Visual acuity of better eye, worse eye, and eye to be operated on for all patients

\begin{tabular}{|c|c|c|c|}
\hline \multirow[b]{2}{*}{ Visual acuity } & Better eye & Worse eye & $\begin{array}{l}\text { Eye to be } \\
\text { operated on }\end{array}$ \\
\hline & No (\%) & No (\%) & No (\%) \\
\hline $6 / 6$ & $37(22.8)$ & $6(3.7)$ & $11(6.8)$ \\
\hline $6 / 9$ & $44(27.2)$ & $21(13.0)$ & $26(16.0)$ \\
\hline $6 / 12$ & $31(19.1)$ & $21(13.0)$ & $28(17.3)$ \\
\hline $6 / 18$ & $33(20.4)$ & $33(20.4)$ & $31(19.1)$ \\
\hline $6 / 24$ & $8(4.9)$ & $30(18.5)$ & $26(16.0)$ \\
\hline $6 / 36$ & $4(2.5)$ & $21(13.0)$ & $15(9.3)$ \\
\hline $6 / 60$ & $0(0)$ & $12(7.4)$ & $10(6.2)$ \\
\hline $\begin{array}{l}\text { Counting fingers, } \\
\text { hand movements, } \\
\text { perceives light only }\end{array}$ & $5(3.1)$ & $18(11.1)$ & $15(9.3)$ \\
\hline
\end{tabular}

There was no statistically significant difference (in terms of age, sex, visual acuity, and number of patients having first eye surgery) between the scale development group and the scale evaluation group.

Table 1 provides information regarding the range of visual acuity of all patients in the study.

CSS SCORES

The CSS was interviewer administered and all patients were able to respond and complete the scale within 5 minutes. The mean instrument score was $29 \%$ (SD 20.7), with scores ranging from 0 to 84 . The median score was $26 \%$ with multiple modes at 5\%, 20\%, and $25 \%$. The Kolmogorov-Smirnov test of normality was $0.96, p=0.004$ indicating a non-normal distribution. One patient scored zero (male, aged 77 years, second eye surgery, visual acuity: $6 / 6$ in aphakic eye and 6/9 in eye to be operated on).

\section{RELIABILITY}

As previously described, the test-retest correlation coefficient for the total instrument score was $r=0.91(\mathrm{p}<0.0001)$; while the coefficient for individual items ranged from $r=0.48$ to $r=$ 0.91 , mean correlation was $0.65(n=50)$. For the 118 patients, internal consistency of the CSS was measured by the Cronbach's alpha coefficient $($ alpha $=0.88)$.

In all, $65 \%$ of patients could complete all of the items of the CSS compared with $1.2 \%$ for the VF-14.

FACTOR ANALYSIS

Principal component factor analysis was undertaken to determine the interrelations of the

Table 2 Factor analysis of the CSS

\begin{tabular}{llll}
\hline & Factor I & Factor II & Factor III \\
\cline { 2 - 4 } & $\begin{array}{l}\text { Sight related } \\
\text { mobility }\end{array}$ & $\begin{array}{l}\text { Recognition } \\
\text { and perception }\end{array}$ & $\begin{array}{l}\text { Hand eye } \\
\text { coordination }\end{array}$ \\
\hline Getting off the pavement & 0.82 & & \\
Going down stairs & 0.75 & & \\
Crossing the road & 0.69 & & \\
Reading small print & & 0.83 & \\
Reading books and newspapers & & 0.80 & \\
Seeing television subtitles/teletext & & 0.72 & \\
Seeing the numbers on a bus & & 0.63 & 0.61 \\
Bright light behind to read & & 0.57 & 0.51 \\
Recognising someone across the street & & 0.55 & \\
Watching television & & & \\
Hot drinks & & & \\
Seeing to write & & & \\
\hline
\end{tabular}

Principal component extraction with Varimax rotation and Kaiser normalisation. different items. The appropriateness of the factor model was assessed by the Kaiser-MeyerOlkin measure of sampling adequacy, which was 0.70 and by Bartlett's test of sphericity, which was 457.9. Both of these are results are satisfactory and demonstrate the legitimacy of the factor analytic procedure. Factors identified may be seen as distinct elements consisting of related symptoms that tend to occur together. For instance, patients who perceived problems negotiating pavements also tended to experience problems with going downstairs. Three factors were identified (Table 2). Three items failed to load against any of the factorsnamely, "recognising coins", "trouble with bright sunlight", and "blurred vision".

Correlations — visual acuity, visual function, health, and psychological status

The results (total score) for the CSS ( $n=118$ ) were compared with results obtained from Snellen visual acuity in the better eye $r=0.52$, worse eye $r=0.33$, operated eye $r=0.25$. For the remaining test battery, correlations were obtained with the VF-14 (visual function) $r=$ -0.83 , the NEADL (activities of daily living) $r$ $=0.52$, the GHQ (perceived health status) $r=$ 0.43 , and HAD (anxiety and depression) $r=$ 0.46. For the patient's global assessment of visual symptoms, a correlation of $r=0.64$ was obtained.

\section{Discussion}

There is increasing awareness of the difficulties and limitations in assessing patients for cataract surgery based on visual acuity data alone. While it is recognised that greatest importance should be placed on the amount the cataract interferes with a patient's functional ability and quality of life, objective measures need to be developed as an adjunct to visual acuity in preoperative assessment. Although measures of glare and contrast sensitivity have been developed, at present there are no standardised measures available and they are not routinely used in clinical practice. ${ }^{18}$ Scales of visual function have already been produced in the USA, but these are not utilised in clinical practice in the UK. A major limitation of existing scales is that they are not wholly appropriate to a UK population, where both sociodemographic factors and other pre-existing medical problems may influence the applicability of some of the items. In a recent study in which the VF-14 was adapted for use in cataract patients in Canada, Denmark, and Spain, only $19 \%$ of the total non-US sample of patients responded to all 14 items in the questionnaire. ${ }^{13}$ In the present study, only $1.2 \%$ of our patients could answer all 14 questions of the VF-14. Much of this difference can be attributed to the fact that many had not previously driven a car and did not participate in hobbies such as tennis, bowls, and golf. Although the VF-14 could have been adapted for use in our population we specifically sought to develop a scale from patients' perceptions of their own problems. Six of the CSS items are similar to items in the VF-14; however, the remaining nine items $(60 \%)$ differ in content from the VF-14, but examine similar aspects of 
visual disability. Using our method of identifying problems with everyday function in cataract patients awaiting surgery we have achieved a scale appropriate to an older UK population. Inevitably some patients will not be able to answer all of the questions in the CSS - for example, those who are housebound for reasons other than visual problems cannot answer questions related to outdoor activities.

We have demonstrated a correlation between the CSS and other measures of functional ability (NEADL), perceived health status (GHQ), and also with patients' own perceptions of how much their visual problems affect their everyday life. This suggests that the CSS is able to identify those patients with significant disability and handicap secondary to their cataracts. Determinants of the need for cataract surgery should include overall functional ability, general health, and patient perceptions, and it is therefore relevant that we have demonstrated a correlation between measures of these variables and the CSS.

We also found a correlation between the CSS and visual acuity in the better eye (as visual acuity decreases the CSS score increases), but not with visual acuity in the eye to be operated on or in the worse eye. Similar findings were observed in studies of the VF-14 suggesting that the ability of a patient to perform sight dependent activities is determined more by vision in the better eye than the worse affected eye. ${ }^{4}$

On the basis of the semistructured interviews we found that the items which patients complained of could be grouped into three main categories, confirmed by subsequent factor analysis. These are (1) sight related mobility, (2) recognition and perception, and (3) hand eye coordination. This implies that the CSS measures areas of functional importance to patients.

As the CSS is a scale for patients with visual impairment it is by necessity interviewer administered. The CSS consists of 15 questions, is easy to administer, and takes only a few minutes to complete. The CSS provides information regarding the symptomatic and functional status of the cataract patient, which will not be recognised by the measurement of visual acuity alone. This information could be used to assist healthcare professionals in identifying clinical need for cataract surgery in older people and hence in prioritisation of access to ophthalmology services. The fact that one of our patients had no perceived visual problems and hence scored zero on the CSS suggests a wide variation in current practice. We propose in a longitudinal study of patients undergoing cataract surgery to identify factors that may be of value in predicting outcome from surgery and thereby developing an algorithm for the preoperative assessment of older patients.

Given the demographic changes in the elderly population and the increase in demand for surgery at the extreme of old age we sought to develop a scale specifically for older people. Consequently the CSS may not be applicable to patients under 65 years of age, although in this group the need for surgery may be much more evident. Irrespective of age, where cataract symptoms threaten driving or employment the CSS may not be wholly appropriate. In our study only $4 \%$ of patients had difficulty driving due to cataracts. The suitability of the scale to those patients under 65 years would need to be assessed in a further study.

The CSS was developed in a cohort of older people living in the north east of England and therefore further work is needed to confirm its general applicability to the UK population. In addition, it will be necessary to determine whether the CSS is responsive to changes in visual symptoms and functional status following cataract surgery.

This study was supported by a grant from Northern and Yorkshire NHS Research and Development Directorate. We are grateful to the patients of South Tyneside for their participation in the study and we thank Julie Brown for help in data in the stud Collection.

1 Courtney P. The national cataract survey: I. Methods and descriptive features. Eye 1992;6:487-92.

2 Hart PM, Chakravarthy U, Stevenson MR. Questionnairebased survey on the importance of quality of life measures in ophthalmic practice. Eye 1998;12:124-6.

3 Mordue A, Parkin DW, Baxter C, et al. Thresholds for treatment in cataract surgery. F Public Health Med 1994;16: 393-8.

4 Steinberg EP, Tielsch JM, Schein OD, et al. The VF-14. An index of functional impairment in patients with cataract. Arch Ophthalmol 1994;112:630-8.

5 Abrahamsson $M$, Carlsson B, Törnquist $M$, et al. Changes of visual function and visual ability in daily life following cataract surgery. Acta Ophthalmol Scand 1996;74:69-73.

6 Schein OD, Steinberg EP, Cassard SD, et al. Predictors of outcome in patients who underwent cataract surgery. Ophthalmology 1995;102:817-23.

7 Lee PP, Hilborne L, McDonald L, et al. Documentation patterns before cataract surgery at ten academic centers. Ophthalmology 1996;130:1179-83.

8 Mangione CM, Phillips RS, Seddon JM, et al. Development of the 'activities of daily vision scale'. A measure of visualfunctional status. Med Care 1992;30:1111-26.

9 Lundström M, Roos P, Jensen S, et al. Catquest questionnaire for use in cataract surgery care: description, validity and reliability. F Cataract Refract Surg 1997;23:1226-36.

10 Pesudovs K, Coster DJ. An instrument for the assessment of subjective visual disability in cataract patients. $\mathrm{Br} \mathcal{F}$ Ophthalmol 1998:82:617-24.

11 Steinberg ER, Tielsch JM, Schein OD, et al. National study of cataract surgery outcomes. Variation in 4 month postoperative outcomes as reflected in multiple outcome measures. Ophthalmology. 1994;101:1131-41.

12 Tielsch JM, Steinberg ER, Cassard SD, et al. Preoperative functional expectations and postoperative outcomes among patients undergoing first eye cataract surgery. Arch Ophthalmol 1995:113:1312-18.

13 Alonso J, Espallargues M, Andersen TF, et al. International applicability of the VF-14. An index of visual function in patients with cataracts. Ophthalmology 1997;104:799-807.

14 Folstein MF, Folstein SE McHugh PR. "Mini-mental state". A practical method for grading the cognitive state of patients for the clinician. $\mathcal{F}$ Psychiat Res 1975;12:189-98.

15 Nouri FM, Lincoln NB. An extended activities of daily living scale for stroke patients. Clin Rehab 1987;1:301-5.

16 Goldberg DP, Hillier VF. A scaled version of the general health questionnaire. Psychol Med 1979;9:139-45.

17 Zigmond AS, Snaith RP. The hospital anxiety and depression scale. Acta Psychiatr Scand 1983;67:361-70.

18 Cataract Management Guideline Panel. Management of functional impairment due to cataract in adults. Guideline report number 4. Rockville, MD. US Department of Health and Human Services, Public Health Service, Agency for Health Care Policy and Research. AHCPR Pub No 93-0541, 1993:28-31. 
Appendix

Cataract symptom scale

Ask before each question "With or without your glasses whichever is better"

\begin{tabular}{|c|c|c|c|c|c|c|c|}
\hline & & \multicolumn{6}{|c|}{ Score } \\
\hline & & 0 & 1 & 2 & 3 & 4 & $N A$ \\
\hline 1 & Do you have difficulty reading small print? & no & a little difficulty & $\begin{array}{l}\text { a moderate amount } \\
\text { of difficulty }\end{array}$ & very difficult & unable to do & $\begin{array}{l}\text { don't do for reasons } \\
\text { other than sight }\end{array}$ \\
\hline 2 & Do you have difficulty watching television? & no & a little difficulty & $\begin{array}{l}\text { a moderate amount } \\
\text { of difficulty }\end{array}$ & very difficult & unable to do & $\begin{array}{l}\text { don't do for reasons } \\
\text { other than sight }\end{array}$ \\
\hline 3 & $\begin{array}{l}\text { Do you have difficulty recognising someone across } \\
\text { the street? }\end{array}$ & no & a little difficulty & $\begin{array}{l}\text { a moderate amount } \\
\text { of difficulty }\end{array}$ & very difficult & unable to do & $\begin{array}{l}\text { don't do for reasons } \\
\text { other than sight }\end{array}$ \\
\hline 4 & $\begin{array}{l}\text { Do you have difficulty seeing the numbers on the } \\
\text { front of a bus? }\end{array}$ & no & a little difficulty & $\begin{array}{l}\text { a moderate amount } \\
\text { of difficulty }\end{array}$ & very difficult & unable to do & $\begin{array}{l}\text { don't do for reasons } \\
\text { other than sight }\end{array}$ \\
\hline 5 & $\begin{array}{l}\text { Because of your eyesight do you have difficulty } \\
\text { going down stairs? }\end{array}$ & no & a little difficulty & $\begin{array}{l}\text { a moderate amount } \\
\text { of difficulty }\end{array}$ & very difficult & unable to do & $\begin{array}{l}\text { don't do for reasons } \\
\text { other than sight }\end{array}$ \\
\hline 6 & $\begin{array}{l}\text { Because of your eyesight do you have difficulty } \\
\text { crossing the road? }\end{array}$ & no & a little difficulty & $\begin{array}{l}\text { a moderate amount } \\
\text { of difficulty }\end{array}$ & very difficult & unable to do & $\begin{array}{l}\text { don't do for reasons } \\
\text { other than sight }\end{array}$ \\
\hline 7 & $\begin{array}{l}\text { Because of your eyesight do you have difficulty } \\
\text { getting off the pavement? }\end{array}$ & no & a little difficulty & $\begin{array}{l}\text { a moderate amount } \\
\text { of difficulty }\end{array}$ & very difficult & unable to do & $\begin{array}{l}\text { don't do for reasons } \\
\text { other than sight }\end{array}$ \\
\hline 8 & $\begin{array}{l}\text { Do you have difficulty reading the subtitles or } \\
\text { teletext on television? }\end{array}$ & no & a little difficulty & $\begin{array}{l}\text { a moderate amount } \\
\text { of difficulty }\end{array}$ & very difficult & unable to do & $\begin{array}{l}\text { don't do for reasons } \\
\text { other than sight }\end{array}$ \\
\hline 9 & $\begin{array}{l}\text { Do you have difficulty reading books or } \\
\text { newspapers? }\end{array}$ & no & a little difficulty & $\begin{array}{l}\text { a moderate amount } \\
\text { of difficulty }\end{array}$ & very difficult & unable to do & $\begin{array}{l}\text { don't do for reasons } \\
\text { other than sight }\end{array}$ \\
\hline 10 & $\begin{array}{l}\text { Because of your eyesight do you have difficulty } \\
\text { pouring a hot drink? }\end{array}$ & no & a little difficulty & $\begin{array}{l}\text { a moderate amount } \\
\text { of difficulty }\end{array}$ & very difficult & unable to do & $\begin{array}{l}\text { don't do for reasons } \\
\text { other than sight }\end{array}$ \\
\hline 11 & $\begin{array}{l}\text { Do you have trouble telling the difference between } \\
\text { coins? (eg, 10p and 50p) }\end{array}$ & no & occasionally & sometimes & most of the time & all the time & \\
\hline 12 & Do you have trouble if you look into bright sunlight? & no & occasionally & sometimes & most of the time & all the time & \\
\hline 13 & Do you use a bright light behind you to read? & no & occasionally & sometimes & most of the time & all the time & \\
\hline 14 & Do you have trouble with blurred vision? & no & occasionally & sometimes & most of the time & all the time & \\
\hline 15 & Do you have trouble seeing to write? & no & occasionally & sometimes & most of the time & all the time & \\
\hline
\end{tabular}

